Arq. Bras. Med. Vet. Zootec., v.53, n.6, p.671-676, 2001

\title{
Estádios de desenvolvimento embrionário de vacas zebuínas superovuladas
}

\author{
[Superovulated zebu cows embryonic developmental stages] \\ J.F. Fonseca ${ }^{1}$, J.M. Silva Filho ${ }^{2}$, A. Pinto Neto ${ }^{3}$, M.S. Palhares ${ }^{2}$ \\ ${ }^{1}$ Doutorando em Zootecnia, Universidade Federal de Viçosa \\ Av. P.H. Rolfs, s/n. \\ 36571-000 - Viçosa, MG \\ ${ }^{2}$ Escola de Veterinária da UFMG. \\ ${ }^{3}$ Instituto de Pesquisa, Estudo e Ambiência Científica da Universidade Paranaense Umuarama, PR
}

Recebido para publicação em 4 de abril de 2000.

Recebido para publicação, após modificações, em 26 de setembro de 2001.

E-mail: fonsecajef@hotmail.com

\section{RESUMO}

O objetivo deste estudo foi relatar o estádio de desenvolvimento de embriões coletados a partir de processos superovulatórios em zebuínos. Foram utilizadas 26 vacas, 16 da raça Nelore Padrão, três da Nelore Mocho, quatro da Gir, duas da Brahman e uma da raça Guzerá. Para o processo de superovulação utilizaram-se 350 UI de FSH em oito doses decrescentes a cada 12 horas, a partir do $10^{\circ}$ dia do ciclo estral (estro = dia 0). Ao sétimo dia após o estro os embriões foram coletados pelo método não cirúrgico e avaliados ao microscópio estereoscópio quanto à qualidade e estádio de desenvolvimento embrionário. Foram coletados 135 embriões viáveis, sendo 68,2\% (92/135) Nelore Padrão, 12,6\% (17/135) Nelore Mocho, 11,1\% (15/135) Gir, 5,2\% (7/135) Brahman e 3,0\% (4/135) Guzerá. Os embriões foram classificados segundo a qualidade em grau I, 51,1\% (69/135), grau II, 43,7\% (59/135), grau III, 4,4\% (6/135), e grau IV, 0,7\% (1/135), e segundo o estádio de desenvolvimento em mórula, 3,7\% (5/135), blastocisto inicial, $16,3 \%$ (22/135), blastocisto, 37,0\% (50/135), blastocisto expandido, 42,2\% (57/135), e blastocisto eclodido, $0,7 \%$ (1/135). Observou-se predominância de estádios embrionários avançados (blastocisto, blastocisto expandido e blastocisto eclodido) que representaram $80 \%$ do total de embriões.

Palavras-chave: Bovino, embrião, superovulação, zebu

\begin{abstract}
This study was carried out with the objective of reporting the developing stages of embryos collected from superovulated zebu cows. Twenty-six zebu cows of Nelore (16), Polled Nelore (3), Gir (4), Brahman (2) and Guzerá (1) breeds were superovulated with 350IU of FSH, divided into eight decreasing doses administered each 12 hours, starting on day 10 of the estrous cycle (estrous = day 0). Seven-day embryos were collected non-surgically and evaluated at microscopy to determine the grade and stage of development. A total of 135 viable embryos were collected, being 68.2\% (92/135) Nelore, 12.6\% (17/135) Pooled Nelore, 11.1\% (15/135) Gir, 5.2\% (7/135) Brahman and 3.0\% (4/135) Guzerá. Embryos were classified according to quality as grade I, 51.1\% (69/135), grade-II, 43.7\% (59/135), grade-III, 4.4\% (6/135), and grade-IV, $0.7 \%$ (1/135), and according to developmental stage in morulae, 3.7\% (5/135), young blastocyst, 16.3\% (22/135), blastocyst, 37.0\% (50/135), expanded blastocyst, 42.2\% (57/135), and hatched blastocyst, $0.7 \%$ (1/135). These results showed the predominance of advanced developing stages (blastocyst, expanded blastocyst and hatched blastocyst) witch represented $80 \%$ of the total of embryos.
\end{abstract}

Keywords: Bovine, embryo, superovulation, zebu 


\section{INTRODUÇÃO}

Em função do importante papel econômico e social dos rebanhos zebuínos na pecuária brasileira e do interesse nacional e internacional na aquisição e multiplicação de animais de elevado valor genético, o mercado de embriões ampliou-se bastante nos anos 1990. Entretanto, grande parte das metodologias e biotecnologias desenvolvidas e utilizadas na obtenção e criopreservação de embriões foram desenvolvidas em taurinos. Por isso, estudos que atendam às peculiaridades fisiológicas dos zebuínos devem ser realizados e poderiam justificar, por exemplo, a maior sensibilidade à criopreservação (Zanenga, 1993) e o estádio de desenvolvimento embrionário relativamente mais avançado dos embriões zebuínos, quando comparados com embriões taurinos coletados no sétimo dia de animais superovulados.

O objetivo deste estudo foi relatar e explicar o avançado estádio de desenvolvimento embrionário apresentado por embriões de vacas zebuínas (superovuladas) coletados no sétimo dia do ciclo estral.

\section{MATERIAL E MÉTODOS}

Foram utilizadas 26 doadoras das raças Nelore Padrão (16), Nelore Mocho (3), Gir (4), Brahman (2) e Guzerá (1), alojadas no Centro de Assessoria Técnica e Transferência de Embriões (CENATTE), município de Pedro Leopoldo-MG. Após seleção e controle do ciclo estral com detecção do estro base (dia-0 ou dia do estro), as fêmeas foram superovuladas a partir do $10^{\circ}$ dia do ciclo estral com hormônio folículo estimulante (FSH) (FSH; Pluset ${ }^{\circledR}$, Serono Veterinária) na dosagem de 350UI, fracionada em oito doses decrescentes, administrados a cada 12 horas, por via intramuscular, durante quatro dias. Cada doadora recebeu duas doses de um miligrama por via intramuscular de um análogo sintético de prostaglandina $F_{2 \alpha}$ $\left(\mathrm{PGF}_{2 \alpha)}\left(\mathrm{PGF}_{2 \alpha} ;\right.\right.$ Cloprostenol, Ciosin®, Coopers do Brasil), 60 e 72 horas após o início da superovulação para indução do estro. Cada doadora foi submetida a três inseminações artificiais (IA). A primeira foi realizada 14 horas após início do estro e as demais a cada oito horas após a primeira.

Os embriões foram coletados pelo método não cirúrgico no sétimo dia do ciclo estral $($ estro $=$ dia 0 ) em meio PBS (tampão salina fosfato) de Dulbecco \& Vogt, modificado por Whittingham (1971), sendo em seguida avaliados ao microscópio estereoscópio segundo a qualidade (Kennedy et al., 1983) e o estádio de desenvolvimento embrionário (Lindner \& Wright, 1983).

Foram utilizados cinco estádios de desenvolvimento: estádio 1 (mórula: aglomerado celular em cuja superfície blastômeros individuais podem ser distinguidos); estádio 2 (mórula compacta: blastômeros individuais não podem ser distinguidos na superfície do embrião); estádio 3 (blastocisto inicial: uma pequena cavidade, a blastocele, está visível e a massa celular interna começa a se formar); estádio 4 (blastocisto: o embrião ocupa a maior parte dentro da zona pelúcida, a massa celular interna começa a tornar-se mais distinta mas o diâmetro global do embrião, incluindo a zona pelúcida, permanece inalterado); e estádio 5 (blastocisto expandido: o diâmetro embrionário está aumentado e a espessura da zona pelúcida pode ser reduzida para aproximadamente $1 / 3$ da espessura original).

Quanto à qualidade, os embriões foram classificados em quatro graus: grau I (excelente: estádio de desenvolvimento com zona pelúcida intacta e esférica, massa celular homogênea com células de tamanho uniforme, nenhum ou poucos fragmentos celulares no espaço perivitelino); grau II (bom: alterações mínimas na forma e coloração com relação ao grau I, alguns fragmentos ou debris celulares no espaço perivitelino e/ou pequenas formações vesiculares nos blastômeros); grau III (regular: claras alterações comparadas com o grau II, embora com a maior parte da massa celular intacta); e grau IV (ruim: muitos fragmentos ou debris celulares no espaço perivitelino, vesículas maiores e em maior número e claras mudanças degenerativas nos blastômeros, com menos da metade da massa celular intacta). 


\section{RESULTADOS E DISCUSSÃO}

O número de embriões viáveis coletados em função da raça da doadora é apresentado na Fig. 1. Obteve-se média geral de 5,2 (135/26) embriões viáveis por doadora. Essa média assemelha-se a resultados obtidos por equipes de transferência de embriões e em estudos anteriores em taurinos (Callesen et al., 1995) que relataram uma média de quatro a cinco embriões viáveis por doadora superovulada.

Dados referentes à qualidade dos embriões coletados são apresentados na Fig. 2. Ressalta-se que a maior parte dos embriões (95\% ou 128/135) foi classificada nos graus I e II (excelente e bom, respectivamente). A média de embriões viáveis obtidas por coleta e a porcentagem de embriões excelentes e bons podem atestar a eficiência dos procedimentos utilizados, dentre eles o do protocolo de superovulação (350UI de FSH). Resultados semelhantes foram encontrados por Munro (1986).

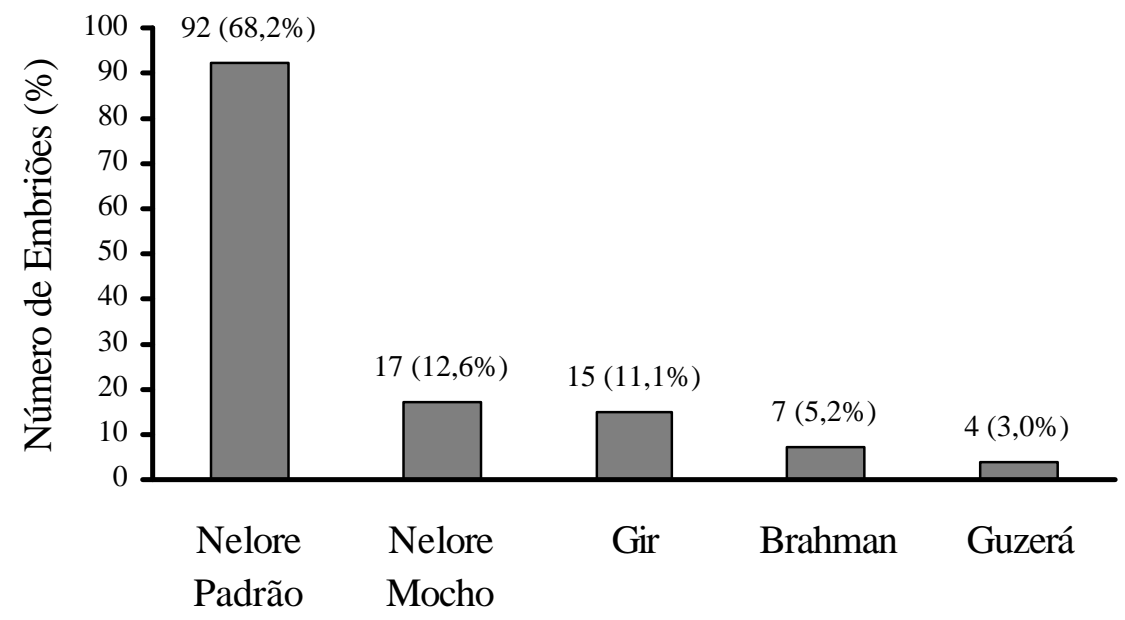

Figura 1. Número de embriões coletados em função da raça da doadora

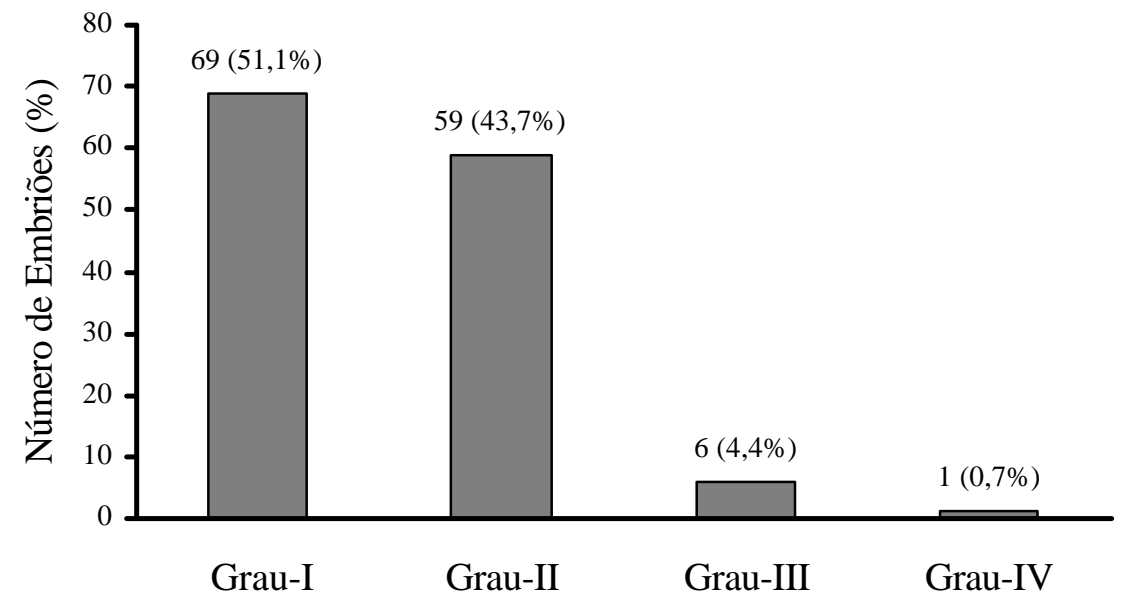

Figura 2. Número de embriões em função da qualidade embrionária 


\section{Fonseca et al.}

Dados referentes ao estádio de desenvolvimento são apresentados na Fig. 3. Observa-se predominância de estádios embrionários avançados (blastocisto, blastocisto expandido e blastocisto eclodido) que representaram $80 \%$ do total de estruturas, contra $20 \%$ de mórulas e blastocistos iniciais. O grande predomínio de estádios avançados de desenvolvimento no sétimo dia após o estro parece ser uma característica marcante que diferencia zebuínos e taurinos. Em um amplo estudo realizado por Callesen et al. (1995), procurou-se identificar os fatores que afetam o estádio de desenvolvimento de embriões taurinos recuperados no sétimo dia após o estro. De 1495 embriões viáveis estudados, 84,5\% encontravam-se em estádios iniciais de desenvolvimento (5,8\% de mórulas, 56,1\% de mórulas compactas e $22,5 \%$ de blastocistos iniciais) e o restante $(15,5 \%)$ em estádios mais avançados $(10,3 \%$ de blastocistos e 5,2\% de blastocistos expandidos). Comparando-se os resultados de Callesen et al. (1995) com os do presente estudo, observa-se que no sétimo dia após o estro houve predominância de estádios iniciais em taurinos, e de estádios mais avançados em zebuínos.

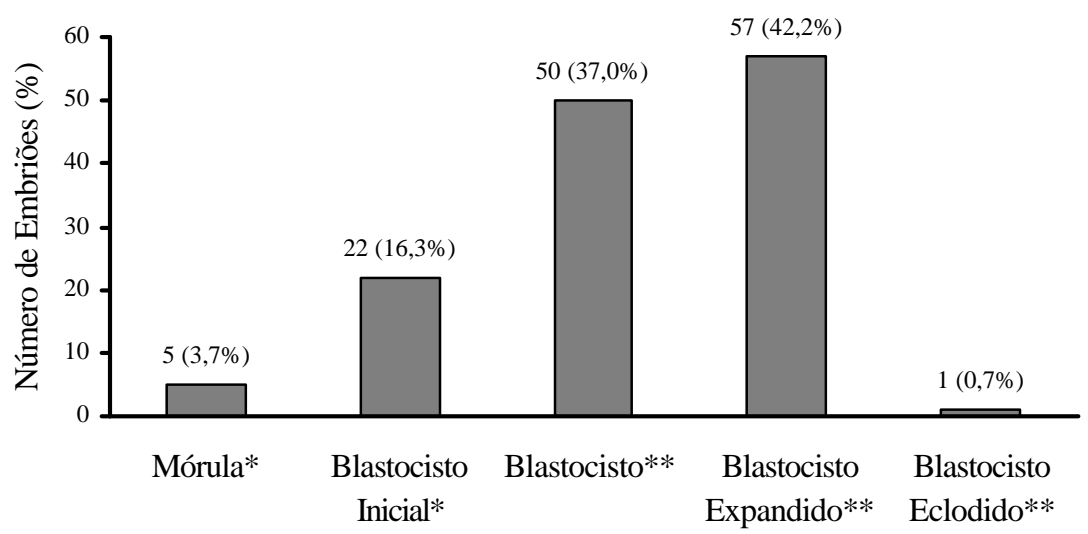

Figura 3. Número de embriões em função do grau de desenvolvimento embrionário (Inicial* e Avançado**)

Algumas diferenças endócrinas poderiam estar contribuindo para a obtenção de estádios embrionários mais avançados em zebuínos quando comparados com os obtidos em taurinos. Fêmeas Bos indicus geralmente atingem a puberdade mais tarde (Plasse et al., 1968a; Dobson \& Kamonpatana, 1986), têm período de gestação mais longo (Plasse et al., 1968b; Dobson \& Kamonpatana, 1986), exibem anestro pós-parto prolongado (Plasse et al., 1968c) e apresentam importante sazonalidade reprodutiva, isto é, tendem a ser acasaladas em dias longos (Chenoweth, 1994). Quanto ao ciclo estral, apresentam estro mais curto (Chenoweth, 1994; Pinheiro et al., 1998) e em menor intensidade, e tendência em não permitir a monta por outras fêmeas.

Outro importante aspecto divergente entre taurinos e zebuínos são as características do corpo lúteo (CL). O CL é primariamente reconhecido por sua habilidade de sintetizar e secretar progesterona (Hafs \& Armstrong, 1968). Segundo Fields \& Fields (1996), o CL formado a partir da hiperplasia e diferenciação das células da granulosa e da teca do folículo ovulatório passa de 200 miligramas no momento da ovulação (células foliculares) a 48 gramas de peso no $11^{\circ}$ dia do ciclo estral nas raças zebuínas. Esse peso é consideravelmente maior nas raças européias. O peso do CL está relacionado com sua capacidade de produzir progesterona, hormônio intimamente relacionado com a manutenção de um ambiente úterotubárico adequado ao desenvolvimento embrionário e manutenção do próprio CL durante o período crítico da vida embrionária (da ovulação à implantação), quando ocorre o reconhecimento materno da gestação (Fields \& Fields, 1996). Fêmeas zebuínas apresentaram CL menor, com menor conteúdo de progesterona por grama de tecido luteal (Segerson et al., 1984). Neste aspecto, estudos anteriores 
reportaram que a detecção do CL por palpação transretal é mais difícil em zebuínos do que em taurinos (Plasse et al., 1968a; Vale Filho et al., 1986). Existem evidências de que o CL de Bos indicus produz menos progesterona do que o de fêmeas Bos taurus (Randel, 1989).

Com relação à ultra-estrutura embrionária, Esper \& Barbosa (1993) encontraram menor área média de mitocôndrias, maior área média de lisossomos (sobretudo nas células trofoblásticas) e menor volume de lipídes em blastômeros de embriões zebuínos em relação aos de embriões taurinos. Talvez a característica mais importante de zebuínos que possa justificar a obtenção de estádios embrionários mais avançados esteja relacionada à ovulação. O hormônio luteinizante (LH), que coordena a ovulação em bovinos, apresenta uma onda pré-ovulatória entre 20 e 22 horas antes da ovulação ou três a seis horas após o início do estro em fêmeas taurinas (Henricks et al., 1970). Isto ocorre mais precocemente em fêmeas zebuínas (Cavalieri et al., 1997). Fêmeas Brahman apresentaram menor conteúdo de LH hipofisário, onda préovulatória de LH mais precoce (Randel, 1976), com menor amplitude e duração (Randel, 1976; Rhodes et al., 1978) e ovulações cerca de 10 horas mais cedo em relação ao início do estro do que fêmeas Hereford (Randel, 1976). Ovulações mais precoces podem refletir em fertilizações também mais precoces, o que daria aos embriões zebuínos tempo adicional para desenvolvimento, permitindo-lhes atingirem estádios relativamente mais avançados no dia da coleta de embriões.

Os resultados deste estudo apontam predominância de estádios embrionários mais avançados de embriões recuperados de vacas zebuínas superovuladas. Esta, entre outras características que diferenciam zebuínos de taurinos, deve ser considerada quando da exploração de embriões em zebuínos.

\section{AGRADECIMENTO}

Ao CENATTE - Centro de Assessoria Técnica e Transferência de Embriões - por ceder os animais, estrutura física e humana, imprescindíveis à realização deste estudo.

\section{REFERÊNCIAS BIBLIOGRÁFICAS}

CALLESEN, H., LOVENDAHL, P., BAK, A. et al. Factors affecting the developmental stage of embryos recovered on day 7 from superovulated dairy cattle. J. Anim. Sci., v.73, p.1539-1543, 1995.

CAVALIERI, J., RUBIO, I., KINDER, J.E. et al.. Synchronization of estrus and ovulation and associated endocrine changes in Bos indicus cows. Theriogenology, v.47, p.801-814, 1997.

CHENOWETH, P.J. Aspects of reproduction in female Bos indicus cattle: a review. Austr. Vet. J., v.71, p.422-426, 1994.

DOBSON, H., KAMONPATANA, M. A review of female cattle reproduction with special reference to a comparison between buffaloes, cows and zebu. J. Reprod. Fertil., v.77, p.1-36, 1886.

ESPER, C.R., BARBOSA, J.C. Ultraestrutura comparativa de embriões bovinos. In: Congresso Brasileiro de Reprodução Animal, 9, 1991, Belo Horizonte. Anais... Belo Horizonte: Colégio Brasileiro de Reprodução Animal, 1991, v.2. p.295.

FIELDS, M.J., FIELDS, P.A. Morphological characteristics of the bovine corpus luteum during the estrous cycle and pregnancy. Theriogenology, v.45, p.1295-1325, 1996.

HAFS, H.D., ARMSTRONG, D.T. Corpus luteum growth and progesterone synthesis during the bovine estrous cycle. J. Anim. Sci., v.27, p.134-141, 1968.

HENRICKS, D.M., DICKEY, J.F., NISWENDER, G.D. Serum luteinizing hormone and plasma progesterone levels during the estrous cycle in early pregnancy in cows. Biol. Reprod., v.2, p.346-351, 1970.

KENNEDY, L.G., BOLAND, M.P., GORDON, I. The effect of embryo quality at freezing on subsequent development of thawed cow embryos. Theriogenology, v.19, p.823-832, 1983.

LINDNER, G.M., WRIGHT Jr., R.W. Bovine embryo morphology and evaluation. Theriogenology, v.20, p.407-441, 1983.

MUNRO, R.K. The superovulatory response of B. Taurus and B. indicus cattle following treatment with follicle stimulating hormone and progesterone. Anim. Reprod. Sci., v.1, p.91-97, 1986. 


\section{Fonseca et al.}

PINHEIRO, O.D., BARROS, C.M., FIGUEIREDO, R.A. et al. Estrous behavior and the estrus-to-ovulation interval in Nelore cattle (Bos indicus) with natural estrus induced with prostaglandin $\mathrm{F}_{2 \alpha}$ or norgestomet and estradiol valerate. Theriogenology, v.49, p.667-681, 1998.

PLASSE, D., WARNICK, A.C., KOGER, M. Reproductive behavior of Bos indicus females in subtropical environment. I. Puberty and ovulation frequency in Brahman and Brahman X British heifers. J. Anim. Sci., v.27, p.94-100, 1968a.

PLASSE, D., WARNICK, A.C., REESE, R.E. et al. Reproductive behavior of Bos indicus females in subtropical environment. II. Gestation length in Brahman cattle. J. Anim. Sci., v.27, p.101-104, 1968 b.

PLASSE, D., KOGER, M., WARNICK, A.C. Reproductive behavior of Bos indicus females in subtropical environment. III. Calving intervals, intervals from first exposure to conception and intervals from parturition to conception. J. Anim. Sci., v.27, p.105-112, 1968c.

RANDEL, R.D. LH and ovulation in Brahman, Brahman X Hereford and Hereford heifers. J. Anim. Sci., v.43, p.300, 1976. (Abstr.)

RANDEL, R.D. Endocrine aspects of zebu cow. In: Congresso Brasileiro de Reprodução Animal, 8, 1989, Belo Horizonte. Anais... Belo Horizonte: Colégio Brasileiro de Reprodução Animal, 1989, v.2. p.1-23.

RHODES III, C.R., RANDEL, R.D., HARMS, P.G. Reproductive studies of Brahman cattle IV. Luteinizing hormone levels in ovariectomized Brahman, Brahman X Hereford and Hereford cows following a 20mg dose estradiol$17 \beta^{\mathrm{a}, \mathrm{b}, \mathrm{c}}$. Theriogenology, v.10, p.429-437, 1978.

SEGERSON, E.C., HNASEN, T.R., LIBBY, D.W. et al. Ovarian and uterine morphology and function in Angus and Brahman cows. J. Anim. Sci., v.59, p.1026-1046, 1984

VALE FILHO, V.R., PINHEIRO, L.E.L., BASRUR, P.K. Reproduction in Zebu Cattle. In: MORROW, D.A. Current therapy in theriogenology 2. Diagnosis, treatment and prevention of reproductive diseases in small and large animals. Philadelphia: W.B. Saunders Company, 1986. p.437-442.

WHITTINGHAM, D.G. Survival of mouse embryos after freezing and thawing. Nature, v.233, n.5315, p.125-126, 1971.

ZANENGA, C.A. Congelação de embriões em zebuínos: evolução e viabilidade. In: Congresso Brasileiro de Reprodução Animal, 10, Belo Horizonte, 1993. Anais... Belo Horizonte: Colégio Brasileiro de Reprodução Animal, 1993, v.2, p.125-130. 